Referencia para citar este artículo: Bolzan Berlese, D., Roese Sanfelice, G., Bolzan Berlese, D. \& Sidegum Renner, J. (2017). Bullying e violência social: vivência de adolescentes obesos. Revista Latinoamericana de Ciencias Sociales, Niñez y Juventud, 15(1), pp. 491-503.

\title{
Bullying e violência social: Vivência de adolescentes obesos*
}

\author{
DENISE BOLZAN BERLESE ${ }^{* *}$ \\ Professora Universidade Feevale, Brasil. \\ GUSTAVO ROESE SANFELICE*** \\ Professor Universidade Feevale, Brasil. \\ DAIANE BOLZAN BERLESE ${ }^{* * * *}$ \\ Professora Universidade Feevale, Brasil. \\ JACINTA SIDEGUM RENNER ${ }^{* * * * *}$ \\ Professora do Programa de Pós Graduação em Diversidade Cultural e Inclusão Social, Brasil.
}

Artículo recibido en abril 11 de 2016; artículo aceptado en julio 5 de 2016 (Eds.)

- Resumo (analítico): Este estudo teve por objetivo desvelar a violência de bullying e violência social por adolescentes obesos. Participaram do estudo 21 adolescentes obesos. Os instrumentos de pesquisa utilizados foram: questionário Kidscape, entrevista semiestruturada, observação participante e diário de campo. Os resultados indicaram que $86 \%$ dos colaboradores sofreram algum tipo de bullying, sendo o local de maior ocorrência o ambiente escolar e se manifestaram na maioria por agressões verbais. Em relação aos processos de exclusão observou-se que os adolescentes obesos sentem-se constrangidos nas relações sociais. O ato do bullying causa sofrimento, no entanto, não os impede de fazer novas amizades e manter seus relacionamentos afetivos e sociais, ou seja, o bullying não os exclui socialmente.

Palavras chave: Adolescentes, obesidade, bullying (Tesauro Biblioteca Virtual em Saúde-BVS).

\section{Bullying and social violence: The experiences of obese adolescents}

- $\quad$ Abstract (analytical): This study had the purpose of highlighting the issue of bullying and social violence committed against obese adolescents. The participants in the study were 21 obese adolescents. The research instruments used included the Kidscape questionnaire, semi-structured interviews, participant observation and a field diary. The results indicated that $86 \%$ of the participants

\footnotetext{
* Este artigo de investigação científica e tecnológica apresenta resultados da investigação denominada: Obesidade de adolescentes como manifestação social a partir do contexto socioeconômico, cultural e familiar, apresentada pela autora para obtenção do título de doutora em diversidade cultural e inclusão social da Universidade Feevale. Toda a investigação ocorreu entre os meses de dezembro de 2014 a novembro de 2015. Processo $\mathrm{N}^{\circ}$ 37542814.0.0000.5348. Área de conhecimento: Ciências Sociais, Subárea: Interdisciplinaridade

** Dra em Diversidade Cultural e Inclusão social-Universidade Feevale. Professora do Curso de Educação Física da Universidade Feevale. Endereço eletrônico: Endereço eletrônico: deniseberlese@feevale.br

*** $\quad$ Dr em ciências da Comunicação-Universidade do Vale do Sinos/Unisinos. Professor do Curso de Educação Física da Universidade Feevale. Endereço eletrônico: sanfeliceg@feevale.br

**** Dra em Bioquímica Toxicológica-Universidade Federal de Santa Maria. Professora de Bioquímica na Universidade Feevale. Endereço eletrônico: daianeb@feevale.br

****** Dra em Engenharia de Produção Universidade Federal do Rio Grande do Sul. Professora Pesquisadora do Programa de Pós Graduação em Diversidade Cultural e Inclusão Social. Endereço eletrônico: jacinta@feevale.br
} 
had suffered from some kind of bullying. The school environment was the place where the highest levels of bullying occurred, which was mostly expressed through verbal aggression. In terms of exclusion processes, it was observed that obese adolescents feel socially uncomfortable. The act of bullying causes them suffering, but it does not prevent them from making new friendships and maintaining their affective and social relationships. Consequently, the authors conclude that bullying does not socially exclude them.

Key words: Adolescents, obesity, bullying (Virtual Library in Health-BVS).

\section{Intimidación como expresión de la violencia social en adolescentes obesos}

- Resumen (analítico): Este estudio tuvo como objetivo revelar la violencia de la intimidación y la violencia social en los adolescentes obesos. Los participantes fueron 21 adolescentes obesos. Como instrumentos de investigación se utilizaron: Cuestionario Kidscape, entrevistas semiestructuradas, observación participante y notas. Los resultados indicaron que el $86 \%$ de los adolescentes ha sufrido algún tipo de intimidación, siendo el lugar más frecuente el ambiente escolar. Los datos expresaron también que el abuso verbal es más frecuente. Respecto al proceso de exclusión se observó que los adolescentes obesos se sienten incómodos en las relaciones sociales. El acto de intimidación causa sufrimiento, sin embargo, no les impide hacer nuevos amigos y mantener sus relaciones emocionales y sociales, es decir, la intimidación no los excluye socialmente.

Palabras clave: Adolescentes, obesidad, acoso escolar (Tesauro Biblioteca Virtual en SaludBVS).

\section{-1. Introdução. -2. Método. -3. Resultado e Discussão. -4.Considerações Finais. -Referências.}

\section{Introdução}

Devido às inúmeras mudanças ocorridas na adolescência, principalmente as decorrentes dos impulsos do desenvolvimento físico, mental, emocional, sexual e social, os indivíduos buscam alcançar os objetivos relacionados às expectativas culturais e sociais (Valente, 2006). Consequentemente, o adolescente, em especial o obeso, está suscetível a não compreender os diferentes processos de mudanças aos quais está passando e, ainda, tende a sofrer com o excesso de peso. Com isso, muitos preconceitos e estigmas surgem em torno do indivíduo obeso.

Com relação ao estigma que tende a acompanhar o adolescente obeso, Goffman (1988) afirma que o indivíduo estigmatizado está inabilitado para aceitação social plena. O estigma social para o obeso é uma barreira complexa a ser ultrapassada, principalmente quando se trata do período da adolescência pois esta é uma fase em que o indivíduo deseja encontrar-se como sujeito e consolidar-se como cidadão.

Os sujeitos são como atores, porém quando um indivíduo obeso é apresentado a alguém, a tendência é pré julgá-lo pela sua identidade social (Goffman, 1988). Ou seja, quando alguém se depara com um sujeito obeso, por exemplo, tende a julgá-lo como uma espécie não desejável, fora dos padrões e acaba reduzindo-o e caracterizando assim, o estigma da obesidade. Mortoza (2011) destaca que os significados sociais construídos a partir da aparência são produzidos pelas relações de diferentes atributos e define a estigmatização social como um desencontro entre identidades. Neste sentido, Queiroz (2000) comenta que é mediante a interação social que o título de anormal é atribuído para pessoas acometidas pela obesidade, o que promove a discriminação social.

Em relação à discriminação, muitos obesos acreditam que os tratamentos discriminatórios sejam naturais. Puhl e Brownell (2001) em seu estudo sobre a estigmatização da obesidade, demonstram que atitudes negativas podem afetar a trajetória pessoal do obeso, ameaçando sua saúde emocional e física.

As crianças e os adolescentes são os líderes quando se considera quem melhor desempenha o papel de estigmatizador. Segundo Puhl e 
Latner (2007), as crianças e os adolescentes são a primeira fonte de estigmatização declarada pelos adultos, sendo o bullying um dos comportamentos mais evidenciados (Mortoza, 2011)

Os fenômenos bullying, mobbing e assédio moral apresentam significados distintos, de acordo com a psiquiatra francesa Marie-France Hirigoyen. Em sua obra "Mal-Estar no Trabalho -Redefinindo o Assédio Moral”, a referida autora menciona que o bullying é mais amplo, refere-se a simples chacotas, piadas, até abuso sexual e violência física- manifesta-se através de ofensas individuais e não organizacional como nos outros dois casos (Hirigoyen, 2002).

A partir dessas considerações, entende-se que o bullying engendra, consequentemente, doenças psíquicas e físicas (psicossomáticas), desordem pessoal e profissional, além de refletir na qualidade e finalidade do processo educativo, bem como na sociedade e na saúde pública (Nascimento \& Alkimin, 2010).

$\mathrm{Na}$ vida em sociedade, há uma ordem consentida em torno da gordura corporal da qual será construído um universo simbólico. A gordura está associada a um valor negativo nas relações sociais e, embora isso não se ensine, essa distinção ao "contrário" opera como um critério de classificação e organização (Mattos, Perfeito, Carvalho \& Retondar, 2012).

Diante do cenário até então exposto, podese dizer que as consequências do bullying para as vítimas parecem ser inúmeras. O bullying como forma de violência é uma temática atual e complexa de ser estudada, uma vez que esse tipo de violência parece causar danos físicos e morais, gerando constrangimento social ao acometido. A partir desse contexto, o objetivo desta pesquisa foi investigar a percepção dos adolescentes obesos sobre os processos de inclusão e exclusão social, bem como, desvelar a vivência de bullying e a violência social.

\section{Método}

O estudo se caracteriza como descritivo, com análise e discussão de dados realizados sob o paradigma qualitativo. Participaram do estudo 21 adolescentes obesos em tratamento no ambulatório de sobrepeso e obesidade de um hospital de alta complexidade, da Região Central do Rio Grande do Sul. Foram incluídos todos os adolescentes que frequentavam o ambulatório por um período superior a um ano, apresentavam assiduidade nos encontros e aceitaram participar do estudo após assinatura do Termo de Consentimento Livre e Esclarecido para menor. Os adolescentes que não atenderam a esses critérios foram excluídos do estudo. Como instrumentos de pesquisa foram utilizados o questionário Kidscape, respondido pelos adolescentes, para identificação de bullying, entrevista semi estruturada, observação participante e anotações em diário de campo. As anotações realizadas em diário de campo correspondem a 300 horas de observação das atividades realizadas no Ambulatório. As entrevistas foram gravadas por gravador de voz digital Powerpack ${ }^{\circledR}$ DVR-2072 e transcritas ipsis literis, sendo o registro acompanhado de algumas anotações.

O estudo foi aprovado pelo Comitê de Ética em Pesquisas da Universidade Feevale, sob o número de registro 37542814.0.0000.5346 de acordo com as determinações da resolução 466, de dezembro de 2012, do Conselho Nacional de Saúde.

Para análise das informações, utilizouse a técnica de análise de conteúdo, proposta por Minayo (2007). que consiste em três etapas distintas: Pré-análise: realizou-se a escolha do material analisado, mediante uma leitura exaustiva, para internalizar o conteúdo, a retomada das hipóteses e dos objetivos iniciais da pesquisa, no que diz respeito ao material qualitativo; Exploração do material: transformaram-se os dados brutos, a fim de compreender o texto, por meio da construção de índices para a quantificação, classificação, reunião e escolha de categorias teóricas e empíricas, que especificarão os temas e Tratamento dos resultados, interferência ou interpretação: investigaram-se os resultados brutos, ou seja, as categorias que foram utilizadas como unidades de análise de maneira que permitam ressaltar as informações obtidas (Minayo, 2007). 


\section{Resultado e Discussão}

Observou-se, por meio das respostas do questionário Kidscape que $86 \%$ (tabela 1) dos colaboradores sofreram algum tipo de bullying. A partir das anotações do diário de campo realizadas através das observações participantes no ambulatório evidenciou-se que que o comportamento agressivo de quem pratica bullying é originado na infância e adolescência

$\mathrm{Na}$ tabela 1 observa-se a ocorrência e a frequência de Bullying em adolescentes obesos.

Tabela 1. Ocorrência e frequência de bullying em adolescentes obesos.

\begin{tabular}{|l|c|c|}
\hline Ocorrência e frequência de bullying (N) & n & \% \\
\hline Você já sofreu bullying (21) & & \\
\hline Sim & 18 & 86 \\
\hline Não & 3 & 14 \\
\hline Quantas vezes (18) & & \\
\hline Diversas vezes & 7 & 39 \\
\hline Várias vezes ao dia & 4 & 22 \\
\hline Uma vez & 3 & 17 \\
\hline Quase todos os dias & 4 & 22 \\
\hline
\end{tabular}

Referente aos dados apresentados na tabela 1 constata-se que a maioria dos adolescentes $(86 \%)$, ou seja, 18 adolescentes frequentemente sofrem algum tipo de bullying. Nesse sentido Caliman (2006) aponta que o bullying, ou as consequências dessas agressões tendem a gerar dificuldades no convívio nos diferentes contextos, ou seja, têm o reforço das circunstâncias ambientais intrafamiliares, extrafamiliares e intraescolares Assim, dos 18 adolescentes que sofrem bullying ao responderem quantas vezes sofreram com essa agressão, 39 \% relatam sofrer diversas vezes.

A questão do bullying vem emergindo com dramaticidade em todas as classes sociais, alarmando pais e a sociedade civil. Diariamente, os diferentes meios de comunicação têm divulgado atos de violência cometidos por adolescentes. As agressões físicas e verbais entre crianças e adolescentes são cada vez mais recorrentes e, em crianças e adolescentes obesos, parecem ser mais evidentes. Em uma sociedade bioascética, onde as questões mais valorizadas são corporais e as identidades são predominantemente somáticas, é de se esperar que ocorram casos de bullying relacionados à aparência corporal. A obesidade na infầncia e na adolescência talvez seja o fenômeno social que mais agregue vítimas e algozes (Ascèse, 2008).

$\mathrm{Na}$ tabela 2, apresenta-se os dados referentes aos locais de maior ocorrência de bullying.

Tabela 2. Locais de ocorrência de bullying de adolescentes obesos.

\begin{tabular}{|l|c|c|}
\hline Locais de ocorrência de bullying & $\mathbf{n}$ & $\mathbf{\%}$ \\
\hline Na sala de aula & 11 & 61,11 \\
\hline Indo e/ou vindo da escola & 2 & 11,11 \\
\hline No pátio da escola & 5 & 27,77 \\
\hline Em outro lugar & 1 & 5,55 \\
\hline
\end{tabular}

Em relação aos locais de maior ocorrência, $61,11 \%$ dos adolescentes investigados (tabela 2) relatam que o bullying ocorre dentro do ambiente escolar, geralmente, na sala de aula.
Em pesquisa realizada na cidade de Salvador, constatou-se, em média, uma ocorrência diária de violência dentro das salas de aula (Nascimento \& Alkimin, 2010). 
Segundo dados do Inquérito Viva -Vigilância de Violências e Acidentes- realizado pelo Ministério da Saúde nos anos de 2006 e 2007 (Brasil, 2009), a violência entre jovens foi a maior causa de morbimortalidade nesta faixa etária, e os locais mais frequentes de ocorrência apontados no ano de 2007, foram a via pública, a residência e a escola. Há ainda que se levar em conta os altos índices de subnotificação. A esse respeito Sposito (2001), em revisão da pesquisa brasileira sobre o tema da violência escolar, identifica dificuldades na aferição da magnitude do fenômeno, em razão de poucas iniciativas na coleta de informações, faltando consistência no monitoramento e registro das ocorrências.

Diversos estudos têm identificado um crescimento na violência escolar nas últimas décadas, destacando ocorrências como a depredação de patrimônio, furtos, roubos, agressões físicas e verbais entre estudantes. A violência nas escolas é um fenômeno complexo e múltiplo que necessita melhor compreensão de suas origens. Entorno e ambientes violentos nas proximidades da escola aumentam os riscos de violência dentro dela (Sposito, 2001; HidalgoRusmussen \& Hidalgo-San Martin, 2015).

A escola é um espaço que reflete a violência e também favorece o aparecimento da violência. No espaço escolar, podem ocorrer diversas manifestações, como a violência física, a simbólica ou institucional e as microviolências, caracterizadas por atos de incivilidade, humilhações, falta de respeito. Esses fenômenos se combinam e se reforçam mutuamente (Ristum, 2004).

Quanto às consequências do bullying para a vida (tabela 3), 44,5\% dos colaboradores relatam que tiveram algumas consequências ruins. $(33,33 \%)$ dos adolescentes apontou que o bullying não traz consequências para suas vidas. No que tange aos pensamentos dos adolescentes frente a quem os agride $55,55 \%$ expõe não gostar de quem comete esse tipo de agressão e $61,12 \%$ atribuem a culpa pela agressão ao agressor. Quando questionados acerca do bullying (tabela 3 ), $88,88 \%$ responderam que sabem o significado da palavra.

Tabela 3. Consequências e sentimentos do bullying em adolescentes obesos.

\begin{tabular}{|l|c|c|}
\hline Consequências e sentimentos em relação ao bullying (N) & $\mathbf{n}$ & $\mathbf{\%}$ \\
\hline Consequências do bullying (18) & & \\
\hline Algumas consequências ruins & 8 & 44,5 \\
\hline Não teve consequência & 1 & 33,33 \\
\hline Fez com que eu mudasse de escola & 1 & 5,55 \\
\hline Consequências terríveis & 1 & 5,55 \\
\hline Senti-me assustado & 1 & 5,55 \\
\hline Consequências terríveis & & \\
\hline O que você pensa de quem pratica bullying (18) & 10 \\
\hline Não gosto deles & 6 & 55,55 \\
\hline Tenho pena deles & 2 & 33,33 \\
\hline Não penso nada & & \\
\hline Quem é o culpado pelo fato de você sofrer bullying(18) & 4 & 22,22 \\
\hline Dos pais deles & 1 & 5,55 \\
\hline Da direção da escola & 11 & 61,12 \\
\hline Quem agride & 2 & 11,11 \\
\hline De quem é agredido & & \\
\hline Você sabe o que é bullying (18) & 16 & 88,88 \\
\hline Sim & 2 & 11,11 \\
\hline Não &
\end{tabular}


Para Barros (1993), na adolescência, os amigos têm imenso valor para ajudar a lidar com os sentimentos complexos e com os conflitos. Daí a importância de que o adolescente tenha amizades, sinta-se aceito e integrado a um grupo. Essa identificação minimiza a sensação de estranhamento.

Portanto, é possível mensurar através das respostas de nossos adolescentes que o bullying traz consigo consequências ruins, uma vez que a vítima sente-se exposta em relação aos demais, devido aos maus-tratos, apelidos pejorativos e agressivos que recebe por estar acima do peso. Assim, através do estigma representado simbolicamente por sinais de incapacidade, inferioridade, ou ainda, de anormalidade diante da obesidade, ocorre um molde na identidade social (Goffman,1988).

Diante das agressões sofridas, os adolescentes obesos sofrem problemas em relação ao seu reconhecimento social e à valorização do eu enquanto sujeito, o que exacerba o estigma do "ser diferente". Dessa forma, diante de apelidos pejorativos lançados à sua pessoa, o obeso estigmatizado se reconhece, ou melhor, é convencido de que o seu papel como agente social não tem valor, sendo preciso optar por duas escolhas: mudar e tornar-se melhor perante aos demais ou continuar sendo um sujeito diferente e inferior. Assim, quando um indivíduo sofre bullying, o que é ressaltado são seus apelidos depreciativos, como "baleia", "elefante", "hipopótamo", entre outros. A representação simbólica desses termos perante o estigmatizado perpassa o senso de simples palavras e o representa como alguém sem qualidades sociais (Mattos et al., 2012).

A consequência imediata do bullying é o dano moral, ou seja, aquele que se traduz em sofrimento imediato, em decorrência da lesão à dignidade e à personalidade. O bulliyng está relacionado à honra da vítima, à saúde e à sua integridade física e psíquica.

Quanto as principais formas de bullying sofridas (tabela 4), $95 \%$ dos adolescentes apontam que as agressões mais frequentes são as verbais, sendo que muitos ao lerem as demais alternativas tiveram dúvidas se assédio sexual e racismo eram considerados bullying. Portanto, pode-se perceber que o conhecimento dos adolescentes obesos sobre esse tipo de agressão ainda é limitado, uma vez que consideram somente agressão física e verbal como bullying.

Tabela 4. Principais formas de bullying em adolescentes obesos.

\begin{tabular}{|l|c|c|}
\hline Principais formas de agressão (N=18) & n & \% \\
\hline Verbal & 17 & 95 \\
\hline Física & 1 & 5 \\
\hline Assédio Sexual/ racismos & 0 & 0 \\
\hline
\end{tabular}

Nota-se que, na sociedade em que vivem muitos dos jovens agredidos, a concepção de violência não é necessariamente a mesma de outros povos e culturas, sendo necessário levar em consideração o ambiente sócio-históricocultural em que ela se manifesta.

Abramovay (2006) alerta que a violência é um fenômeno de difícil conceituação, pois depende das inter-relações entre os sujeitos no ambiente social em que ocorre o ato. Minayo e Souza (1999) concordam que "é muito difícil conceituar a violência, principalmente por ser ela uma forma própria de relação pessoal, política, social e cultural; por vezes, uma resultante das interações sociais, um componente cultural naturalizado".

Em pesquisa sobre juventude e violência no Brasil, a Unesco (2001) destaca que não há apenas uma violência, mas, sim, uma abundância de ações violentas, que merecem o reconhecimento a partir do contexto sóciohistórico vivenciado. Essas ações violentas acabam gerando, na maioria dos casos a exclusão social que caracteriza-se por uma variedade de problemas socioeconômicos e culturais (Proença, 2005).

$$
\text { Para Les-Baupin (2000) o conceito }
$$
de exclusão está presente em todos os 
países, independentemente do seu nível de desenvolvimento, tendo em comum a questão social. O conceito de exclusão e inclusão social foi sendo modificado conforme a época e situação, caracterizando-se por uma definição aberta e flexível, entretanto há um consenso de que a exclusão se manifesta com as privações de direitos e uma distinção conceitual de pobreza (Borba \& Lima, 2011).

A exclusão social se estabelece pela negação a certos indivíduos ou grupos devido a desigualdades. Todavia, a inclusão social preza pela equidade. Logo, o fenômeno de exclusão social pode ser compreendido como um processo que abrange a todos com condições e níveis diferenciados. Além dos recursos financeiros e materiais, a exclusão social engloba aqueles que são limitados por uma causa ou uma diversidade, por exemplo, os portadores de uma doença, como a obesidade (Wixey, Jones, Titheridge \& Chistodoulou, 2005).

Nessa perspectiva, a obesidade na adolescência surge como uma patologia estigmatizadora, que tende a excluir o sujeito de atividades cotidianas e do contexto social onde está inserido. O preconceito, a discriminação, os problemas de saúde físicos e psíquicos são fatores presentes na vida de todo o obeso. Entretanto, a obesidade nem sempre é interpretada sob a ótica da saúde. No decorrer da história, a obesidade foi vista de diferentes formas.

Entretanto, com o passar dos séculos, muitas mudanças ocorreram e ser obeso passou a ser visto como algo indesejável. No início do século XX, há uma ênfase ao corpo esbelto, reconhecendo que o corpo, que antes era sinônimo de beleza e sucesso, agora representa um mal à saúde. Portanto, a valorização exacerbada da aparência física passa a depender mais do corpo, dando início aos rigorosos regimes, cirurgias plásticas e, consequentemente, aos distúrbios alimentares (Mota, 2012).

$\mathrm{Na}$ atualidade, a sociedade concebe como belo o corpo magro e esbelto, sendo, portanto, a gordura rechaçada, favorecendo a exclusão. Neste contexto, ocorreu relato de um dos colaboradores que foi nomeado de Ingá. Este, ao ser questionado se já deixara de realizar alguma tarefa por estar acima do peso, relatou da seguinte forma:

"Olha, eu não gosto de jogar bola na escola. $\mathrm{Na}$ verdade, eu não jogo bem, e não me convidam muito para jogar. Geralmente, eu fico no gol. Como eu sou grande, eu defendo bem. Mas, se eu pudesse, eu não jogava".

No mesmo contexto, Goivo acrescenta que já se sentiu excluído por estar acima do peso:

"Já. Assim, meus colegas às vezes, eu me sinto excluído pelo meu peso. Eles me deixam fora das atividades às vezes, mas não é sempre. Aí eu saio de perto. Eu falo só pra mãe".

Nesse sentido, Cassia Rosa aborda que também já se sentiu excluída,

"Sim, foi no colégio assim, mas só no colégio, nada mais".

A partir dos relatos expostos, nota-se que os adolescentes se sentem excluídos ou se excluem de algumas atividades, em especial em atividades esportivas, o que causa sofrimento e constrangimento, gerando insegurança. Esse sentimento, de quem está inseguro com relação a seu corpo, afasta-os de atividades que possivelmente contribuiriam para uma melhor socialização, principalmente no contexto escolar.

Para Mota (2012), na infância, os problemas relacionados à obesidade se iniciam na escola, sejam pelos apelidos maldosos impostos pelas crianças, ou pelas dificuldades em participar de atividades físicas e/ou brincadeiras, gerando ainda mais frustração.

No contexto familiar também há evidências de exclusão. Ingá, ao ser questionado sobre como é seu relacionamento com seus familiares, coloca:

"Quem me incomoda um pouco é meu irmão mais velho, ele me chama de gordo. $\mathrm{Eu}$ já to indo na academia para perder peso e ele segue me chamando de gordo. $\mathrm{Eu}$ acho que pra ele parar de me chamar de gordo, eu tenho que ficar magro como ele..."

$\mathrm{Na}$ fala de Ingá, percebe-se o esforço, sem reconhecimento, para perder peso. Vindo ao encontro da fala de Ingá, Clusia corrobora dizendo: 
“...Eu me dou bem com a minha mãe, com meu pai. Tirando as brigas com meu irmão... é bom, ele me chama de gorda."

Além de Ingá e de Clusia, Gloriosa também diz se sentir incomodada com os comentários de um irmão, ao relatar:

"É com meu irmão... ele fica me chamando de gorda toda a hora."

Percebe-se concordância na fala de Ingá, de Clusia e de Gloriosa, ficando evidente que os entrevistados se sentem incomodados com as agressões verbais dos irmãos. Segundo Ingá, o irmão diz estar cansado de ver sua falta de motivação para emagrecer. Ingá também atribui a sua obesidade ao pai, que também está acima do peso. Quando a mãe é questionada sobre as agressões verbais que Ingá sofre em casa pelo irmão, ela afirma:

"O Ingá é gordo mesmo, não se ajuda."

Com isso, evidencia-se que a mãe age exatamente como o filho mais velho, desconsiderando o problema e atribuindo toda a culpa e responsabilidade ao adolescente obeso. Puhl e Brownell (2001), ao descreverem a estigmatização da obesidade, demonstram que atitudes negativas em relação aos obesos podem se transformar em verdadeiras discriminações e afetar as trajetórias sociais dos indivíduos acometidos pela patologia. Uma criança excluída dentro de seu contexto familiar pode apresentar distúrbios emocionais graves, uma vez que a polarização do peso existe em diferentes contextos. A expansão da exclusão para além do contexto familiar parece estar vinculada às relações interpessoais com os familiares.

As sociedades ocidentais tendem a considerar os indivíduos que estão acima do peso como fora dos padrões de normalidade para um ideário de massa corporal. Tais imperfeições sinalizam não somente deformidades corporais, mas também estão associadas a traços negativos de caráter (Queiroz, 2000). É no curso das interações sociais que o rótulo de anormal é atribuído aos indivíduos, que, além de serem rotulados, são julgados fora da normalidade, porque não aderem às normas sociais vigentes. Desse modo, uma série de discriminações sociais ocorre em diferentes contextos, dentre elas está a exclusão (Goffman, 1988).
Quando questionados sobre se sentirem excluídos em algum lugar por ser obesos, Ingá expõe isso da seguinte forma:

"Agora não mais, mas quando eu era menor sim. Agora, acho que as pessoas já se acostumaram com meu jeito de ser assim, um pouco mais gordinho."

Relata ainda sentir-se estigmatizado dentro de casa pelo irmão, porém, como a agressão parte de um familiar, o adolescente não a interpreta como um fator de exclusão, e sim como algo natural.

Marlieira também aborda que já se sentiu constrangida por estar acima do peso, dificultando suas relações sociais:

"Ah, sei lá, eu tinha vergonha de conversar com os outros. Eu sempre fui gordinha, eu tinha vergonha dos outros, porque eu era gorda e diferente de todo mundo. As pessoas te tratam diferente quando tu é gorda, agora que eu tô mais menos gorda, não tenho tanta vergonha, aí eu faço mais amigos, converso na escola, e tem os amigos do bairro também que a gente se reúne de vez em quando para fazer umas reuniões".

Outro colaborador, aqui nomeado de Neem, traz uma fala muito marcante que expressa todo esse sentimento de impotência frente à exclusão no contexto escolar, ao comentar:

"Já. Não sei, eles ficam num lado e eu fico no outro... eles não me aceitam". Acerca do relatado, Neem é questionado se esta exclusão ocorre em razão da obesidade. Em reposta, afirma que sim, dizendo "eu acho".

A partir da fala dos entrevistados evidenciase que alguns já foram excluídos pelo fato de estarem acima do peso e se sentiram envergonhados com a condição de obesidade. Segundo Felippe (2001), as pessoas obesas tendem a sofrer discriminação e preconceitos que levam ao isolamento social, devido ao excesso de peso.

Entretanto, atualmente, os entrevistados acreditam que, pelo fato de seus amigos também estarem acima do peso, a exclusão parece ter sido minimizada, como se observa na fala de Ingá: 
“... E outra, né, eu nem tenho mais tantos colegas magros que possam me debochar, aí fica fácil, né (Risos)".

Marlieira menciona que foi excluída na infância, mas que, no momento, devido à sua maturidade, a exclusão não é evidenciada como antes:

"Sim, eu já fui muito excluída, mas agora não sou mais. Acho que foi bem pelo que eu te disse antes. Antes eu era mais na minha e me irritava o que as pessoas falavam. Eu ficava braba e triste, agora já não dou mais bola. As pessoas que falem o que elas quiserem. Já me chateie muito com essas coisas, e por isso acho que não tinha tanto amigos. Agora que não dou mais bola vi que as pessoas que andam comigo não se importam se eu to gorda, se eu to magra, eles gostam de mim pelo que eu sou não pelas coisas que eu tenho".

Por meio dos relatos acima, é possível perceber que os adolescentes obesos sentiamse excluídos quando eram crianças, mas, na adolescência, esse sentimento modificou-se, pelo fato de uma grande parte das pessoas com quem convivem também se encontrar na mesma condição, ou seja, com excesso de peso. Entretanto, Papiro relata que já percebeu algumas atitudes de seus colegas que podem ser interpretadas como uma atitude de exclusão, todavia não de forma explícita:

“... já vi desconfiança, um olhar diferente, mas nunca falaram assim, na cara. Nunca me deixaram fora de nada por eu tá acima do peso."

Os demais adolescentes colaboradores do estudo não relataram se sentirem excluídos de seus ambientes de convívio o que remete a uma tendência mundial que aborda que a obesidade está atingindo níveis alarmantes, principalmente na faixa de idade da adolescência. Segundo, Neutzling et al. (2000) a prevalência de adolescentes obesos na região sul do país é de $13,9 \%$ para ambos os sexos, já para Monteiro et al. (2000), 24,5\% dos adolescentes apresentam sobrepeso e $9 \%$ obesidade. Para Abrantes, Lamounier y Colosimo (2002), a prevalência de obesidade em adolescentes variou entre $6,6 \%$ e $8,4 \%$, nas regiões Nordeste e Sudeste, respectivamente.
A partir da observação participante realizadas no ambulatório pressupõem que, na adolescência, as brincadeiras adotam outra conotação, uma vez que passam a ser interpretadas como algo natural ou de menor importância. As mudanças de biótipo que acontecem na adolescência fazem com que as questões relacionadas à obesidade não demandem tanta atenção. $\mathrm{Na}$ adolescência, apesar da preocupação natural com as modificações corporais, o ser obeso parece não representar uma condição agravante para a exclusão. Dessa forma, a adolescência, por representar um período de mudanças psicofísicas, que influenciam questões sociais, psicológicas e a constituição do sujeito, traz consigo inúmeras indagações acerca do futuro. Dentre essas indagações e incertezas, está o modo como se relacionar com os demais e com o sexo oposto.

Dessa forma, ao serem questionados sobre como estabelecem as suas relações afetivas e se o fato de estar acima do peso os prejudica na conquista, os adolescentes respondem:

"Acho que não tem nada a ver, se a guria gosta de mim, acho que não teria problema de eu ser gordo. Acho que não tem nada a ver" (Ingá).

Para Alferes (2000), os fenômenos de atração dizem respeito aos componentes afetivos das relações sociais, em particular, às atitudes, às emoções e aos sentimentos positivos que os sujeitos experimentam na relação com os outros, ou seja, a aparência não parece ser tão fundamental quanto os atributos que têm relação com o comportamento e com o caráter de cada um.

As questões que interferem nas relações afetivas, principalmente no que tange ao "ficar" e namorar foram expressas da seguinte forma por Marlieira:

“... Eu sempre quis ficar com ele, mas ele nunca me dava bola... Aí a gente ficou, mas foi só uns beijos, nada de mais... Só que depois da festa, ele nem me olha mais, tá tudo bem que antes ele não falava comigo, mas agora acho que ele nem sabe que eu existo".

A partir do depoimento das adolescentes, Marlieira, observa-se que os comportamentos 
dos adolescentes obesos em relação aos laços afetivos são semelhantes aos demais jovens de sua faixa de idade, ou seja, a obesidade parece não estar impedindo que eles se relacionem afetivamente, bem como, não causa nenhum tipo de empecilho no ato da conquista. Jesus (2005), em seu artigo intitulado: "Ficar ou namorar: um dilema juvenil" corrobora com o relato de Marlieira sobre os pretendentes, afirmando que, atualmente, os jovens estão preferindo relacionamentos passageiros e sem compromissos reais.

Constata-se também que, atualmente, os adolescentes têm apresentado uma fluidez ou uma navegação social em relação aos seus modos de interagir socialmente, independente de estarem ou não acima do peso. Essa fluidez/ navegação é caracterizada pela variedade de relacionamentos afetivos e sociais que esse grupo tem. Com esse novo comportamento surgem modalidades que incluem relações pautadas no namoro e no sentimento, bem como as relações instantâneas, momentâneas, correspondendo a necessidades físicas e fisiológicas, sem continuidade ou aprofundamento na vida dos adolescentes, uma delas é o "ficar" (Oliveira, Gomes, Marques \& Thiengo, 2007).

Trata-se, portanto, de um mundo que não favorece a criação de vínculos duradouros, à associatividade e à grupalização. Nesse cenário, o adolescente se vê impelido a instituir o modo típico de relacionamento desse tempo: relações abreviadas, voltadas para a satisfação de necessidades e desejos imediatos, sem compromissos que ultrapassem o momento da relação.

Os relacionamentos contemporâneos estão instantâneos, ou seja, possuem a exata duração da confluência de demandas efêmeras, já que se renovam continuamente e se multiplicam. Parece não haver lugar para relacionamentos duradouros articulados a um projeto futuro, capazes de catalisar demandas diversas e estabilizar relações, especialmente aquelas que circunscrevem pares, casais, pequenos agrupamentos e espaços afetivos locais (Justo, 2005).

Ao encontro do que Justo (2005) expõe, a colaboradora Girassol relata:
"Não tenho paquera fixa, sou nova, to só curtindo."

No mesmo sentido, Gloriosa e Luca corroboram ao comentar:

"Não to com ninguém sério. Eu fico de vez em quando (Gloriosa)."

"Não, to ficando direto... Dificuldade eu não sinto, já fiquei com bastantes gurias. Sério não. O peso não é problema."

Álamo também contribui dizendo que costuma "ficar" com as garotas que consideram bonitas:

"... Eu consigo ficar com as gurias. A dificuldade é só com algumas. Eu me interesso por algumas delas e elas não dão bola, mas se alguma delas tá a fim de mim, às vezes eu nem fico sabendo. Eu só fico com quem eu acho bonita...".

Todavia, o colaborador Neem encontra dificuldades em ficar, mas não atribui isso ao sobrepeso. Nesse sentido, aborda:

"... eu nem sempre consigo ficar com todo mundo que eu quero". “... Tem guri maior que eu que fica com as gurias, não tem nada a vê."

Quando questionado sobre o local onde julga ser mais acessível "ficar" comenta:

"Nas festas é mais difícil, sei lá é mais difícil. É porque a gente não tá sempre junto como na escola."

A partir dos relatos até então expostos, constata-se que "o ficar" é uma das maneiras mais utilizadas pelos adolescentes para se relacionar afetivamente. O "ficar" é também uma oportunidade de autoconhecimento, pois não se cria vínculos afetivos concretos, com isso é possível "ficar" com muitas pessoas sem que seja determinado um compromisso afetivo. Os adolescentes relatam que o ato de "ficar" ocorre, principalmente, em festas, casas de amigas e no intervalo das aulas na escola. Sendo que muitos reconhecem que esse tipo de relacionamento não irá determinar o futuro afetivo.

Nesse sentido, Giddens (2002), aponta que o romantismo está fincado na promessa e em seu lugar surge uma forma de amor e relacionamento amoroso plástico: o amor confluente e o relacionamento puro. Neles, o afeto e o relacionamento são contingentes e estão 
baseados numa negociação de correspondência dentro de uma relação horizontalizada entre homem e mulher, que é inspirada em valores de igualdade entre as partes. $\mathrm{O}$ amor confluente, diferentemente do abnegado amor romântico, dura enquanto durar a cosatisfação entre os parceiros (Justo, 2005).

$\mathrm{Na}$ contrapartida do exposto te então, três colaboradores relataram vivenciando um relacionamento mais sério, conforme expresso por Cássia Rosa:

“... ele tem 18 anos. Aí agora ele vai ir lá em casa. Antes dele eu tive dificuldade de encontrar alguém por tá gordinha. Eles não queriam ficar comigo. Eu acho que era pelo peso. Esse agora é um bebezão, uma criança (risos)."

Narciso também comenta que está com uma pessoa. O "estar" nessa perspectiva, significa que está envolvido:

"Tô com uma guria. Ela é da minha escola". Angico corrobora dizendo: "Tenho uma paquera. Ela não fala que eu tô acima do peso. Já faz dois meses que tô com ela. Ela é da minha escola".

Diferentemente do ficar, o namoro é visto, na cultura ocidental, como uma relação afetiva constante e duradoura, tendo o compromisso como um elo e a afetividade sempre presente. Pfromm-Netto (1976) afirma que o namoro geralmente começa como uma experiência pouco duradoura e superficial de contato entre os jovens, como o ficar, pois para manter vínculos duradouros é necessário maturidade e experiência (Jesus, 2005).

Sendo assim entende-se que em relação aos laços afetivos estabelecidos na adolescência, observa-se que o comportamento dos adolescentes se assemelha aos demais da sua faixa etária. Alguns ainda estão vivenciando relacionamentos passageiros e somente "ficando", mas outros, já estão investindo em relacionamentos com critérios mais estabelecidos como o "namoro". Por fim, cabe ressaltar que parece que os adolescentes definem a si mesmos a partir de suas ligações sociais e do modo como interagem com o grupo de colegas. Conviver com seus pares ajuda-os a criar um senso de identidade e pertencimento.

\section{Considerações Finais}

Acerca da percepção dos adolescentes obesos sobre os processos de exclusão e inclusão social, pode-se dizer que estes entendem que durante a infância sofreram mais bullying e se sentiam mais excluídos do que na adolescência. Justificam essa percepção, ao entenderem que, na fase da adolescência, as chacotas e os apelidos atribuídos ao fato de serem obesos acabam tendo outra conotação. Para esses jovens, apesar da preocupação com as modificações corporais, que é característica dessa fase da vida, o "ser obeso" parece não representar uma condição agravante para a exclusão social.

Em termos de relacionamentos, os adolescentes dizem não sofrer discriminação ou rejeição do sexo oposto e expressam que preferem relacionamentos passageiros e sem compromissos. Adotam a condição de "ficar", ou seja, suas ações não diferem dos demais jovens de sua faixa de idade. Portanto, parte-se do pressuposto que a obesidade parece não estar impedindo seus relacionamentos afetivos, bem como, entendem que não lhes causa empecilho ao ato da conquista.

Após compreender a ocorrência de bullying e investigar os processos de inclusão e exclusão de obesos, o estudo permite inferir que há uma diferença entre sofrer bullying e sentir-se excluído. A partir da percepção dos adolescentes o bullying não impede que façam novas amizades e mantenham seus relacionamentos afetivos e sociais. Isso remete à reflexão de que a ao afirmarem não se sentirem excluídos, há uma tendência de utilizarem isso como subterfúgio para sublimar o sofrimento que os acomete desde a infância.

Dessa forma, o bullying é uma manifestação social da obesidade, pois carrega significados - representações sociais de um corpo que extrapola o peso corporal físico e individual. Compreendendo o social como a rede de relações entre as pessoas, observa-se que o bullying envolve estigmas, discriminações e preconceitos.

Sobre o referido acima, indica-se que o primeiro mecanismo para que o adolescente obeso seja compreendido em sua totalidade, 
é a efetivação de práticas integradas e ações preventivas, a partir da instituição de programas sociais que oportunizem a aquisição de competência desses adolescentes. Assim, será possível informar, sensibilizar, conscientizar e mobilizar os envolvidos com a obesidade. Acredita-se que, por meio de investigações em pesquisa, será possível promover a instrumentalização dos profissionais de saúde, assim como, os educadores e os familiares para as questões relacionadas ao bullying e a inclusão e exclusão desses adolescentes no contexto familiar e social

A partir do exposto, pode-se inferir que um quadro completo em termos de manifestação de bullying na adolescência demandaria estender a exposição além do que é o propósito deste estudo, respeitando diferentes contextos sociais e ampliando a população investigada.

\section{Referências}

Abramovay, M. (coord.) (2006). Cotidiano nas escolas: Entre violência. Brasília: Unesco, Observatório de Violência, Ministério da Educação.

Abrantes, M., Lamounier, J. \& Colosimo, E. (2002). Prevalência de sobrepeso e obesidade em crianças e adolescentes das regiões Sudeste e Nordeste. Jornal de Pediatria, 78, pp. 335-40. Doi: 00217557/02/78-04/335.

Alferes, V. A. R. (2000). Atracção interpessoal, sexualidade e relações íntimas. In J. Vala, M. B. Monteiro (coords.) Psicologia Social, (pp. 125-158.) Lisboa: Fundação Calouste Guebenkian.

Ascèse, F. (2008). Dictionnaire du Corps. Paris: CNRS.

Barros, C. S. G. (1993). Pontos de Psicologia do Desenvolvimento. São Paulo: Ática.

Borba, A. A. \& Lima, H. M. (2011). Exclusão e inclusão social nas sociedades modernas: Um olhar sobre a situação em Portugal e na União Europeia. Serviço. Social e Sociedade, 106, pp. 219-240.

Brasil (2009). Viva: vigilância de violências e acidentes, 2006 e 2007. Brasília: Ministério da Saúde.
Caliman, G. (2006). Estudantes em situação de risco e prevenção. Ensaio: Avaliação $e$ políticas públicas em Educação. Acesso em: <http://www.scielo.br/ scielo.php? script $=$ sci_arttext $\&$ pid $=$ S0104-40362006000300007>

Felippe, F. (2001). O Peso Social da Obesidade. Acesso em: <http://encipecom.metodista. br/mediawiki/images/7/72/GT7-texto4_O_peso_social_da_obesidade-_Flavia. pdf.> Acesso em: 12 abr. 2014.

Giddens, A. (2002). Modernidade e identidade. Rio de Janeiro: Jorge Zahar.

Goffman, E. (1988). Estigma: Notas sobre a manipulação da identidade deteriorada. Rio de Janeiro: Livro Técnicos e Científicos Editora.

Hidalgo-Rausmussen, C. \& Hidalgo-San Martín, A. (2015). Violencia e inseguridad contextual percebida y roles em bullying em escolares mexicanos. Revista Latino Americana de Ciências Sociales, Niñes $y$ Juventud, 13 (2), pp.767-779. Doi: 10.11600/1692715x.13215021214.

Hirigoyen, M. F. (2002) Mal-Estar no Trabalho: Redefinindo o assédio moral. Rio de Janeiro: Bertrand Brasil.

Jesus, J. S. (2005). Ficar ou namorar: Um dilema juvenil. Revista de Psicologia, 6 (1), pp. 67-73.

Justo, J. S. (2005). O "ficar" na adolescência e paradigmas de relacionamento amoroso da contemporaneidade. Revista do Departamento de Psicologia-UFF, 17 (1), pp. 61-77.

Les-Baupin, I. (2000). Poder local x exclusão social: A experiência das prefeituras democráticas no Brasil. Petrópolis: Vozes.

Mattos, R. S., Perfeito, R., Carvalho, M. C. \& Retondar, J. (2012). Obesidade e bullying na infância e adolescência: $\mathrm{O}$ estigma da gordura. Demetra, 7 (2), pp. 71-84.

Minayo, M. C. de S. \& Souza, E. R. (1999). É possível prevenir a violência? Reflexões a partir do campo da saúde pública. Ciência \& Saúde Coletiva, 4 (1), pp. 7-23.

Minayo, M. C. de S. (2007). O desafio do conhecimento: pesquisa qualitativa em saúde. São Paulo: Hucitec. 
Monteiro, P. O. A. et al. (2000). Diagnóstico de sobrepeso em adolescentes: Estudo do desempenho de diferentes critérios para índice de massa corporal. Revista de Saúde Pública, 34, pp. 506-13. Doi 10.1590/ S0034-89102006000500011.

Mortoza, A. S. (2011). A obesidade como expressão de questão social: Nutrição e estigma. Tese Doutorado, UNB. Brasília, D. F., Brasil.

Mota, D. C. L. (2012). Comportamento Alimentar, ansiedade, depressão e imagem corporal em mulheres submetidas a cirurgia bariátrica. Dissertação (Mestrado Psicologia), Universidade de Ribeirão Preto, São Paulo, Brasil.

Nascimento, G. A. F. \& Alkimin, M. A. (2010). Violência na escola: O bullying na relação aluno-professor e a responsabilidade jurídica. Anais XIX encontro nacional do Conpedi realizado em Fortaleza, Brasil.

Neutzling, M. B. et al. (2000). Overweight and obesity in Brazilian adolescents. International Journal of Obesity, 24, pp.869-874.

Oliveira, D. C., Gomes, A. M., Marques, S. C. \& Thiengo, M. A. (2007). "Pegar", "ficar" e "namorar": Representações sociais de relacionamentos entre adolescentes. Revista Brasileira de Enfermagem, 60 (5), pp. 497-502.

Pfromm-Netto, S. (1976). Psicologia da Adolescência. São Paulo: Pioneira.

Proença, C. S. (2005). A exclusão social em cabo verde: Uma abordagem preliminar. Lisboa: Acep-Associação para a Cooperação entre Povos, Centros de Estudo do Instituto Superior de Economia e Gestão da Universidade Técnica de Lisboa.

Puhl, R. \& Brownell, K. (2001). Bias, dsicrimination, and obesity. Obesity research, 9, pp.788-905. Doi: 10.1038/ oby.2001.108.

Puhl, R. \& Latner, J. (2007). Stigma, obseity and the healt of the nation's children. Pchychological bulletin, 133 (4), pp.557580. Doi: 2007-09203-001.

Queiroz, R da S. (2000). O corpo do brasileiro: Estudo de estética e de beleza. São Paulo:

Senac.
Ristum, M. (2004). Violência: Uma forma de expressão da escola? Aprender. Caderno de Filosofia e Psicologia da Educação, 2, pp. 59-68.

Sposito, M. P. (2001). Um breve balanço da pesquisa sobre violência escolar no Brasil. Educação e Pesquisa, 27 (1), pp.87-103.

Unesco (2001). Abrindo espaços: Educação e cultura de paz. Brasília: Unesco.

Valente, P. B. (2006). Alimentação Saudável na Adolescência. Acesso em: <http:// www.diaadiaeducacao.pr.gov.br/portals/ cadernospde/pdebusca/producoes pde/2009 unioeste ciencias artigo cleuza_helena_perazolo_de_alme.pdf $>$

Wixey, S., Jones, P., Titheridge, H. \& Chistodoulou, G. (2005). Measuring Accessibility as Experienced by Different Socially. London: University of Westminster. 